\title{
Subjetividade, política, cultura:eixos para pensar a entrevista midiática como fonte para a pesquisa científica $^{1}$
}

Daniela Silva da Silva²

Resumo: Em 2007, o historiador Paulo Cesar de Araújo é processado pelo cantor Roberto Carlos, pela publicação de uma biografia não-autorizada, lançada em 2006. O caso repercute na mídia e termina em acordo entre as partes. Desde então, muitas são as fontes que disseminam ideias produzidas a partir desse acontecimento histórico. Dentre estas, duas entrevistas, em programas de televisão, disponíveis no YouTube: a primeira concedida por Roberto Carlos, ao Fantástico, em 27/10/2013, e a segunda, por Paulo César de Araújo, ao Roda Vida, em 28/10/ 2013. Tomando esses materiais e em diálogo inicial com Benveniste, Bakhtin, Barthes e Arfuch, o artigo problematizará o gênero entrevista midiática como fonte à pesquisa científica, no intuito de pensar os dilemas e afetos entre público e privado na contemporaneidade, intercambiando três eixos temáticos: subjetividade, política e cultura.

Palavras-chave: Subjetividade. Política. Cultura. Entrevista. Pesquisa Científica.

\begin{abstract}
In 2007 Brazilian historian Paulo Cesar de Araújo is legally processed by the singer Roberto Carlos for publishing an unauthorized biography released in 2006. The case reverberates in the media and is closed after an agreement between parts. Since then, many sources have been disseminating ideas produced by this historical event. Among them two interviews on television programs available on YouTube. The first, given by Roberto Carlos to Fantástico on 27.10.2013, and the second by Paulo César de Araújo to Roda Vida on 10.28.2013. 28/10/2013. Taking into account these materials and also in an initial dialogue with Benveniste, Bakhtin, Barthes and Arfuch the this article will problematize the media interview genre as a source for scientific research, in order to think about the dilemmas and affections between public and private in contemporary times, crossing over three axes thematic: subjectivity, politics and culture.
\end{abstract}

Keywords: Subjectivity. Politics. Cultures. Interview. Scientific Research.

\footnotetext{
1 Este trabalho resulta de uma comunicação apresentada no VII Congreso Internacional de Historia Oral de la República Argentina: "Historia y memórias: ¿Hacia una Pluralidad de Voces?”, no ano de 2018, em Trelew, Argentina, como parte das pesquisas aprofundadas no Pós-Doutorado, realizado Programa de Pós-Graduação da Faculdade de Ciências Sociais, da Universidade de Buenos Aires, no mesmo ano, com supervisão da Profa. Dra. Leonor Arfuch.

2 Graduada em Letras (FURG), Mestre e Doutora em Teoria da Literatura (PUCRS), com Pós-doutorado no Programa de Ciências Sociais da Universidade de Buenos Aires. Professora do Departamento de Letras e do Programa de Pós-Graduação em Letras da Universidade Estadual do Centro-Oeste (Unicentro/Guarapuava-Pr). Currículo Lattes: http://lattes.cnpq. br/2173977742532214.
} 


\section{Inscrições teóricas}

A intersubjetividade tem assim sua temporalidade, seus termos, suas dimensões. Por aí se reflete na língua a experiência de uma relação primordial, constante, indefinidamente reversível, entre o falante e seu parceiro. Em última análise, é sempre ao ato de fala no processo de troca que remete a experiência humana inscrita na linguagem.

Émile Benveniste, Problemas de linguística geral II

$\mathrm{Na}$ Ilíada, o poeta-locutor invoca uma divindade para cantar a cólera de Aquiles. Instaura, assim, o tempo da narrativa. Ao fazê-lo, cria uma relação de co-presença. Um eu se dirige a um tu, para falar de um terceiro e de sua paixão; falarão de Aquiles, que, assim como as demais personagens da obra atribuída a Homero, entrará em diálogo, direto e indireto, referido pelo locutor, dizendo de si e de outros. Ao narrar, ao colocar seu discurso no mundo, o poeta mostra o lugar em que suas criaturas aparecerão, o que, também, sucessivamente, será feito por cada uma delas.

Este comportamento é característico de situações de enunciação. Onde está um eu está um tu, bem como a reversibilidade das posições ocupadas pelos locutores, no momento em que duelam na e pela alocução. É, portanto, no caráter dialógico que se funda a temporalidade do discurso, pelo sentimento de continuidade e consecução dos atos de fala, (in)determinados pelas escolhas feitas por locutoras e locutores ao se apropriarem particularmente de uma língua.

$O$ uso que fazemos da língua para esta reflexão instaura uma temporalidade em que dialogam pessoas discursivas, as quais trazem para o discurso científico as implicâncias do ficcional, possibilitando, assim, pensar os fatos sociais como uma trama complexa verossímil entre otridades de diferentes naturezas e/ou campos do saber. A obra de Homero instaura o espaço de fala, em que trataremos, primeiramente, do texto de Émile Benveniste, Problemas de linguística geral II, por meio do capítulo "O aparelho formal da enunciação", para emprestar do linguista francês sua discussão sobre três funções enunciativas, das qual os interlocutores se valem a fim de influenciar alocutários. A primeira delas é a interrogação:

\begin{abstract}
que é uma enunciação construída para suscitar uma "resposta", por um processo linguístico que é ao mesmo tempo um processo de comportamento com dupla entrada. Todas as formas lexicais e sintáticas da interrogação, partículas, pronomes, seqüência, entonação, etc., derivam deste aspecto da enunciação. (BENVENISTE, 1989, p. 86).
\end{abstract}

Além da interrogação, a intimação, que se define por: "ordens, apelos concebidos em categorias como o imperativo, o vocativo, que implicam uma relação viva e imediata do enunciador ao outro numa referência necessária ao tempo da enunciação". Em terceiro lugar, apresenta a asserção, cuja presença, ainda que menos evidente, "visa a comunicar uma certeza, ela é a manifestação mais comum da presença do locutor na enunciação" (BENVENISTE, 1989, p. 86), expressa pelas palavras sim e não. "De modo mais amplo, ainda que de uma maneira menos categorizável, organizamse aqui todos os tipos de modalidades formais", sendo "uns pertencentes aos verbos, como os "modos" (optativo, subjuntivo) que enunciam atitudes do enunciador do ângulo daquilo que enuncia (expectativa, desejo, apreensão)", enquanto "outros a fraseologia ("talvez", "sem dúvida", "provavelmente") e indicando incerteza, possibilidade, indecisão, etc., ou, deliberadamente, recusa de asserção". (BENVENISTE, 1989, p. 87)

Um ato de enunciação põe em contato figuras do discurso e suas experiências humanas, as quais mobilizam o aparelho de funções constituído pela interrogação, intimação e asserção. Benveniste pensa a intersubjetividade desde um ponto de vista enunciativo. Por essa razão, permite-nos olhar o discurso e ver sua estrutura interna: "na enunciação, a língua se acha empregada para a expressão de uma certa relação com o mundo" (BENVENISTE, 
1989, p. 84). Há um processo de referenciação e colocução no emprego da língua por um determinado locutor, alternadamente. Benveniste pressupõe a relação da língua com o mundo. É Mikhail Bakhtin, por sua vez, quem amplia o debate ao propor em seus estudos a polifonia dos discursos e a relação indispensável da língua com a cultura, por meio da alteridade e do plurilinguismo, especialmente no caso do discurso romanesco.

Assim como o romanesco, o gênero entrevista midiática também pode ser estudado desde as perspectivas de Benveniste e de Bakhtin, as quais sucedem o trabalho estruturalista de Ferdinand de Saussure, avançando numa perspectiva cultural. Tanto Benveniste (1989) quanto Bakhtin (2018) estão preocupados com o estudo das subjetividades e das situações de comunicação. Especialmente este último com as hibridizações de vozes que dialogam no interior dos enunciados. Em seu El espaço biográfico, Dilemas de la subjetividade contemporânea, refletindo sobre os mesmos estudiosos, Leonor Arfuch (2010,) aponta que "toda entrevista es entonces ejemplo paradigmático de esa apertura a la otredad que es fundamento de la teoría bajtiniana". Para a autora, "Otredad del linguaje, habitado por voces ajenas, de la comunicación, como tensión hacia ese otro para y por el cual cada enunciado tiene lugar". Tal citação faz um link com uma nota de rodapé, no mesmo livro: "una de las diferencias entre Benveniste e Bajtín es precisamente la idea de simultaneidad (dialógica) versus la idea de sucesión: para Benveniste, los partícipes de la comunicación son alternativamente protagonistas, en tanto asumen, a su turno, el 'yo' de la enunciación” (ARFUCH, 2010, p. 127). Enquanto Benveniste pressupõe a sucessividade do protagonismo de quem fala, Bakhtin aponta a simultaneidade dos interlocutores. Não há centralidade no discurso para este.

Uma vez que a entrevista é utilizada nas pesquisas cientificas como metodologia para a investigação científica, e tendo em vista que se constitui por sua (inter)subjetividade, indo teoricamente na contramão dos discursos de atestação de veracidade, parece-nos que a ciência da linguagem proposta por Benveniste, com suas categorias formais, possíveis de serem mensuradas, problematizam, à primeira vista, o tema da confiabilidade das fontes. A subjetividade expressa na língua, conforme as apropriações de um indivíduo ao se inscrever no discurso, confere materialidade, concretude, a um estudo. Por outro lado, não apenas a imanência da língua, mas seu dialogismo interno e externo, dado pela presença da outridade, da cultura, também importam quando se trata da subjetividade como fonte para a pesquisa científica. Nesse caso, o espaço biográfico criado pela entrevista é plurivocal e, por essa razão, político. A entrevista midiática, pois, não vem para assegurar a verdade, mas para construir possibilidades de verdades, que contam com linguístico e o semiótico. Especialmente num contexto em que se fala de crise das representações, mesmo assim, num sentido ainda que não mimético, mas quiçá, com índices aristotélicos, a lógica da pergunta e da resposta, a interrogação, que também é o ato disparador da investigação científica, constituase e esteja perpassada por gestos que focalizam a verossimilhança e a necessidade demandada por um trabalho de investigação.

Nesse sentido, o gênero do discurso que aqui se expressa por meio das entrevistas escolhidas, como partes de um projeto de investigação que vem se constituindo temporalmente, no andamento da pesquisa, e no diálogo entre fontes, oferece-nos a oportunidade de refletir, conforme as subjetividades nelas inscritas, acerca dos dilemas entre público e privado, na contemporaneidade, trama essa que se arma por meio de narrativas não menos complexas que os sujeitos que nelas se enunciam. Tais dilemas merecem destaque porque emanam do debate que emergiu a partir do fenômeno da proibição das 
biografias, em que se pautou o direito à privacidade e à liberdade de expressão ao mesmo tempo, especialmente no caso do livro de Paulo Cesar de Araújo, Roberto Carlos em detalhes. Por conseguinte, discutir os afetos presentes no discurso, em função do desagrado que causou nos indivíduos, parece-nos um ponto de partida para entender o que disparou os desafetos, os quais produziram ressignificações sociais e jurídicas. Para tanto, intercambiamos três eixos temáticos: subjetividade, política e cultura.

Tomando o aparelho de funções proposto por Benveniste, interessa-nos pensar as entrevistas concedidas por Roberto Carlos ao Fantástico e Paulo César de Araújo ao Roda Viva. Posteriormente, a partir do funcionamento da língua no discurso e em relação à cultura, num determinado suporte midiático, o meio, discutir como os atos de fala demonstram relações de simultaneidade e sucessão, conforme as propostas de Benveniste, sem deixar de dialogar com outras fontes teóricas, tendo em vista, conforme Arfuch (1992) a interioridade pública da entrevista como gênero, o que já demonstra sua ambivalência como traço de constituição. Para tanto, apresentamos esta reflexão na forma de artigo, em quatro partes, sendo esta, a primeira delas, de caráter introdutório. $\mathrm{Na}$ segunda, discutiremos os aspectos relativos aos suportes e aos formatos em que são veiculadas. Do aparelho em funcionamento, ocupamo-nos na terceira, que tratará do estudo das transcrições textuais das entrevistas em vídeo, bem como de um comparativo entre elas, sem deixar de ver os gestos corporais implicados, a partir de enfoque discursivo, através do qual problematizamos o gênero enquanto particularidade constituinte da história oral, portanto, das Ciências Sociais. Nesta parte visamos, ainda, propor uma tipologia da entrevista, construída a partir das fontes aqui trabalhadas, na qual se agrupam quatro modalidades: 1 . onisciente ou didático-demiúrgica, 2. atestação da verdade,

3. expositiva auto-reflexiva, 4. contraposição, 5. inquérito. Por último, um fecho para as ideias, com alguns apontamentos.

\section{Aspectos do suporte e do formato da entrevista midiática}

Ao analisar uma entrevista midiática veiculada em um programa de televisão é preciso ter em conta a ideologia da emissora em que aparece e sua legitimidade no espaço social, como formadora de opinião - além da estrutura dos programas e o enfoque. O Fantástico, no ar desde 1973, é exibido semanalmente, aos domingos à noite, na Rede Globo, emissora privada, que nasceu em 1965, e tem sede no Rio de Janeiro. Tal é o espaço em que é apresentada a entrevista de Roberto Carlos. Segundo Eliana Regina Munhoz (2008, p.37) ${ }^{3}$, "o que distingue a formação da Rede Globo de Televisão das demais emissoras que iniciaram a operação em rede na mesma época”, conforme discute em sua dissertação de mestrado, é o fato de ela ter captado primeiramente a visão de vocação capitalista da televisão comercial". O Roda Viva, por outro lado, no ar há mais de 30 anos, programa em que é exibida a entrevista de Paulo Cesar de Araújo, é veiculado pela TV Cultura, ligada à Fundação Padre Anchieta, "instituição pública que recebe recursos do Estado de São Paulo"4. Ambos são canais de televisão abertos ao púbico, o que não significa que sejam gratuitos.

Diferentemente do Fantástico, que também conta com entrevistas em sua programação, o Roda Viva se caracteriza por ser unicamente voltado para a realização de entrevistas ${ }^{5}$. O primeiro se estrutura 3 A história da Rede Globo e suas afiliadas é abordada na Dissertação de Mestrado: "A Rede Globo de Televisão no território brasileiro através do sistema de emissoras afiliadas", de autoria de Eliana Regina Munhoz. Disponível em: https:/ / www.teses.usp.br/teses/disponiveis/8/8136/tde-04112009151837 /publico/ELIANE_REGINA_MUNHOZ.pdf. Acesso em: 14 de dezembro de 2018.

4 Dados obtidos do site da TV Cultura. Acesso em 24 de mai. Disponível em http://fpa.com.br/sic/.

5 Para um leitura sobre uma parte da história do Programa, consultar http://www.editoranobel.com.br/ arquivos/2007487.pdf. 
pela variedade de cenários e métodos de abordagens dos temas e ideais e vem se transformando esteticamente ao longo de seu histórico vida. Por seu turno, o segundo, ocupa-se de entrevistar variadas personalidade e abordar diferentes assuntos, apresentando modificações na estética do cenário ao longo dos anos, bem como mantendo método e formato únicos: acontece em um espaço circular, lembrando a arena de um coliseu, com bancadas, em que ficam os entrevistadores, enquanto o entrevistado está no centro da roda. A abertura do programa remete a essa descrição, uma vez que a câmera, em espiral, gira até encontrar o sujeito-entrevistado, para, finalmente, chegar ao mediador, à época da entrevista com Paulo Cesar de Araújo, o jornalista Augusto Nunes. No caso das entrevistas veiculadas pelo Fantástico, o espaço varia. Em virtude da configuração do lugar, a conversa com Roberto Carlos parece ter sido realizada em seu estúdio de gravação particular, obedecendo à praxe das cores que atendem aos gostos do cantor, o azul e o branco.

O caráter de formação das emissoras permite já de início estabelecer uma discussão entre público e privado. No caso da Rede Globo, por se tratar de uma empresa privada, orienta-se para fins em comum com a sociedade capitalista de consumo. O produto vendido ao público é a informação, que por sua vez forma a Sociedade dos indivíduos, para lembrar o livro de Norbert Elias, e é formada por ela. E não podemos deixar de considerar, por isso, o atributo de gerador de opinião dos meios de comunicação, bem como que o direito de concessão de emissoras de televisão é dado pelo Governo Federal, tendo a Rede Globo recebido o seu primeiro no período da Ditadura Militar. Os limites entre público e privado são tênues e mostram que no tecido social as instâncias se interseccionam, formando conjuntos híbridos. Sendo assim, se a opinião pública é formada por empresa com interesses privados, a opinião é pública e/ou privada? A TV Cultura, por outro lado, é uma emissora do governo. Diferentemente da Rede Globo, não se apresenta como um produto comercial, que se oporia ao entendimento de uma grade de programação voltada para a sociedade de massa. Trata-se de uma empresa pública.

Além do enfoque e da orientação vocacional das empresas, ainda é necessário entender que também o posicionamento e a postura de cada um dos jornalistas interessa à compreensão do assunto, assim como dos convidados a serem entrevistados, e o modo de preparação da pauta. Sendo assim, o que vai ser dito e como isso chegará na casa das pessoas, desde as câmeras até a tela da televisão, e, agora, via internet, no caso do gênero em estudo: a entrevista midiática. Tal posicionamento pode ser percebido não apenas por meio de inscrições políticas declarados ou não, abertamente, por cada pessoa que fala, mas ainda pela estética das perguntas, o tom da voz, os gestos da face, as movidas de corpo, as tomadas de câmera e o cenário escolhido.

No caso da entrevista do Fantástico, o vídeo e a narração da jornalista intercalam-se com o espaço restrito da conversação, delimitando, assim, cenas individuais e em conjunto, público e privado. Ainda que dentro de um contexto em que a imagem do si e do outro estão expostas a todo o país, com câmeras que se alternam, obliquamente, ora em um, ora em outro locutor, há circunstâncias de intimidade. Muitas vezes, com a jornalista de costas para a câmara, como parte do cenário, tendo o público por cima de seus ombros, como um ventrículo; como se o leitor fosse a câmera, no papel de entrevistador, questionando o entrevistado, e como se o programa, com rasgos de "onisciência didático-demiúrgica", soubesse o que o público deseja perguntar, portanto, saber, configurandose, assim, a primeira modalidade da tipologia que queremos construir. 
No caso do Roda Viva, a câmera está no entrevistado, em close-up, enquadrando-o. Outra vezes, nos entrevistadores, quando no ato da pergunta, individual, e se amplia, para mostrar o todo, quando o debate causa comoção geral, demonstrando uma visão panorâmica da cena. Também se afasta do entrevistado e mostra a fisionomia dos entrevistadores, enquanto sua vOz está em pano de fundo, para narrar as reações de cada indivíduo na bancada.

Além disso, as risadas, as miradas, as mãos, a encenação. Os ritos, o vestuário e os gestos, juntamente com a enunciação, são aspectos semióticos que, com os linguísticos, formam um repertório de signos e imagens que permitem compor um fenótipo das subjetividades, dos afetos e das suas relações sociais, cultuais e políticas.

\section{$\mathrm{O}$ aparelho em funcionamento}

$\mathrm{Na}$ entrevista que Roberto Carlos concede ao Fantástico, de que nos valeremos tanto da parte veiculada em vídeo quanto em texto transcrito, é importante analisar o paratexto que antecede as imagens, que tem por legenda: "Roberto Carlos fala sobre polêmica das biografias. $O$ cantor apresentou um ponto de vista mais flexível do que as ideias que vinha defendendo. Ele revelou que

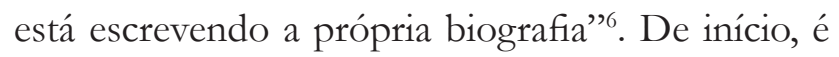
declarada a temática a ser abordada e a personagem a ser entrevistada. Além da legenda, a introdução do assunto, as nuances de fala, o cenário, as entradas no palco do programa, nesse caso, cada um dos dois jornalistas à sua vez, Renata Vasconcelos e Tadeu Schmidt, os gestos com o corpo, o tom de voz, o monitor ao fundo, com imagens do cantor, sem referências a Araújo, que é citado quando se trata de indicar autoria, e aparece quando a capa do livro proibido, Roberto Carlos em detalhes, é projetada

6 GLOBO PLAY. Fantástico. Roberto Carlos fala sobre polêmica das biografias. Disponível em: https://globoplay. globo.com/v/2916608/. Acesso em: 24 de maio 2018. no vídeo introdutório que antecede a entrevista feita pela jornalista.

O lugar de destaque na paisagem da matéria dado às personalidades é o lugar das hipóteses; é onde se pode alocar as ideologias de um programa, bem como as intenções do discurso que irão interpelar o telespectador. As ênfases da fala, a reiteração de imagens projetadas, as figurações, isto é, o modo como cada uma das personagens aparece, assim como a ordem em que isso se dá. As escolhas linguísticas que produzem enunciados revelam concordâncias entre o que dirá o entrevistado e o que já foi antecipado, como focalização externa, num processo de entrevista conforme mencionado: "onisciente ou didática-demiurgica". Nesse caso, também se distingue o gênero pelo aproaching do tema e do entrevistado, os métodos utilizados pelos entrevistadores, os quais constroem subjetividades diante dos telespectadores, formando uma opinião social, afetiva, e modos de sociabilidade dos indivíduos de um determinado contexto sóciohistórico. A conversa entre os jornalistas, portanto, reitera o paratexto e o amplia para anunciar o que virá:

Renata: Pivô dessa polêmica, Roberto Carlos decidiu falar pela primeira vez sobre o assunto e apresentou um ponto de vista mais flexível do que as ideias que vinha defendendo.

Tadeu: O rei conversou com a Renata Vasconcelos e também fez uma revelação: tá preparando a própria biografia ${ }^{7}$.

No diálogo, percebe-se que a interpretação antecede o ato de mostrar a pergunta e a resposta que constituem a performance da entrevista. Ocorre em situações em que a interrogação sobre o outro é feita previamente. Porém, nesse caso, não seria essa a razão mais evidente, se não o fato de que, na sua 7 Roberto Carlos. Entrevista realizada em 27 de outubro de 2013. Entrevistadora: Renata Vasconcelos. Transcrição: Site Fantástico, G1. Disponível em: http://g1.globo. $\mathrm{com} /$ fantastico/noticia/2013/10/roberto-carlos-preparaautobiografia-e-diz-que-vai-falar-de-acidente-na-infancia. $\mathrm{html}$. Acesso em: 24 de maio 2018. 
metodologia interpretativa, o programa prepara a leitura do espectador, com o resumo daquilo que escolhe, seleciona, didaticamente, para informar, explicando o que será visto antes mesmo de sê-lo. Vasconcelos e Schmidt conversam no palco. Estão inscritos na alocução acima mencionada, produzemna, disputam a alternância sucessiva dos lugares de fala, são um eu e um tu da conversa que antecede a entrevista, marcam o dito com entonações, fracas ou fortes, em consonância com gestos corporais que as reafirmam enfaticamente. Isso se lermos um em relação ao outro. Porém, quando se dirigem ao público, são um nós, junto com a emissora, que veicula informações interpretadas, o que poderíamos chamar dentro da nossa proposta tipológica, de entrevista com informação "didático-demiúrgica". A câmera presentifica o outro do discurso dos dois, os quais, observados pelo público, falam sobre um terceiro. Roberto Carlos, por sua vez, é o pivô da polêmica, mas não é, até este momento, protagonista, em primeira pessoa, de nenhum ato de fala. Decidiu falar, sem imposição ou intimação, mas figura em nível de enunciado, por meio de ações verbais: "decidiu", "apresentou", "conversou", "fez", referenciado com substantivos: "pivô", "rei", e é historicamente motivado: "mais flexível", fatos que revelam as expectativas dos enunciadores sobre outrem, que de antemão biografam, linguisticamente, com suas escolhas gramaticais, a personalidade de que falarão, a qual irá ratificar um discurso a posteriori. A fala dos jornalistas, pois, é o a priori. Aqui, propomos um segundo tipo: o da entrevista como "atestação da verdade enunciada", o que nos leva a pensar que o entrevistador assume maior protagonismo que o entrevistado. A entrevista, no caso, "atesta o discurso". Anteriormente à conversa entre Renata e Roberto Carlos, a jornalista, mais uma vez, resume os fatos, por meio de um vídeo, uma narrativa visual, que termina com a entrada do canto no estúdio, para a conversa ${ }^{8}$ :

Renata Vasconcellos: O que você acha do projeto de lei que está no Congresso e que permite, que pretende liberar a publicação de biografias sem a autorização do biografado?

Roberto Carlos: O que eu acho é que tem que se conversar. Tem que se conversar e chegar a esse equilíbrio.

Renata: Especificamente sobre esse projeto de lei, você é a favor ou contra?

Roberto Carlos: Eu sou a favor, eu sou a favor.

Renata: Você mudou de opinião?

Roberto Carlos: Não é que eu mudei de opinião. Há algum tempo, pra gente proteger o direito à privacidade, só existia uma forma. Não permitir uma biografia não-autorizada.

Renata: Contra calúnia, difamação, o caminho da Justiça não basta? Não cabem processos, pedidos de indenização?

Roberto Carlos: É. Só que o resultado vem um pouco tardio. Depois que todo mundo já leu, já viu na internet. Alguns já compraram até os livros, aqueles que foram colocados à venda. Isso não funciona muito não.

Renata: As pessoas não podem julgar pelo critério próprio se vale a pena dar respaldo para o que está escrito ou não? Deixar as pessoas avaliarem?

Roberto Carlos: Não. Nesse caso, não.

Renata: Qual seria o caminho, então?

Roberto Carlos: Conversar, discutir. Chegar a uma

8 Roberto Carlos. Entrevista realizada em 27 de outubro de 2013. Entrevistadora: Renata Vasconcelos. Transcrição: Site Fantástico, G1. Disponível em: http://g1.globo. $\mathrm{com} /$ fantastico/noticia/2013/10/roberto-carlos-preparaautobiografia-e-diz-que-vai-falar-de-acidente-na-infancia. html. Acesso em: 24 de maio 2018. 
conclusão que seja mais razoável pra todo mundo.

Roberto defende que uma nova lei estabeleça limites ao tipo de informação a ser divulgado.

Roberto Carlos: Desde que os juristas, vamos dizer assim, realmente estudem muito bem isso e estabeleçam algumas regras que não prejudiquem o biografado.

Renata: Você hoje é favor das biografias sem autorização prévia?

Roberto Carlos: Sem autorização. Porém, com certos ajustes.

Renata: Que ajustes seriam esses?

Roberto Carlos: Isso aí tem que se discutir. São muitas coisas. Tem que haver um equilíbrio e alguns ajustes para que essa lei não venha a prejudicar nem um lado, nem outro. Nem o lado do biografado, nem o lado do biógrafo. E que não fira a liberdade de expressão e o direito à privacidade. Renata: Você permitiria a biografia que foi feita a seu respeito há alguns anos?

Roberto Carlos: Isso tem que ser discutido.”

Antes de observarmos as questões de fundo temático, importa ressaltar que um dos interrogantes enfrentados numa investigação que tem como corpus a entrevista midiática audiovisual é o fato de que a transcrição do texto oral para o escrito faz com que se perca a totalidade e a literalidade das vozes e dos gestos nos atos de suas enunciações corporais, os quais, mesmo que narrados ou descritos, não refletem sua inteireza de significação. O corpo físico transcende e alcança o corpo da linguagem escrita. Fica registrado, assim, o caráter precário da descrição, porém não menos legítimo, na medida que temos de realizar gestos de supressão e escolha do que problematizar, segundo critérios demandados pelo próprio objeto de investigação. O trabalho de transcrição põe o/a pesquisadora no papel de um Dr. Frankenstein.
Um texto, pois, é uma construção na linguagem das peças que emanam de outro corpo, verbal e não-verbal ao mesmo tempo. O discurso, portanto, é polifônico em termos conteudísticos e formais, assim como homólogo à sociedade, para usar a concepção de Lucien Goldmann, bem como assimétrico, como discute Wolfgang Iser, e por isso não determinista, mas indeterminado, uma vez que resulta das aporias e das assimetrias entre a língua, o discurso e a fala.

Da leitura dessas assimetrias, a entrevista ratifica o que foi antecipado pelos dois jornalistas e pela narração feita no vídeo que antecedeu a conversa. Roberto Carlos diz não ter mudado de opinião e com isso os jornalistas comprovam que sua leitura dos enunciados é verdadeira, e que, portanto, requerem confiabilidade, assim como a emissora que as veicula. O método constrói relações de credibilidade do dito, bem como subjetividades, as quais também podemos perceber por um exame dos gestos, da fisionomia e das palavras escolhidas. Assim como as elipses, os silêncios, os ruídos, as respostas incompletas, as orações concessivas, "desde que", o discurso jurídico, atestado por palavras que atualizam um campo semântico: "permitir", "lei", "direito à privacidade", "liberdade de expressão", também nos permitem ler as relações entre os sujeitos no discurso e a implicação do mundo nos enunciados. As duas últimas, por sua vez, "direito à privacidade" e "liberdade de expressão", especialmente destacáveis, por que com esses sintagmas o debate temático deste artigo é retomado: os embates entre privado e público, os quais estão na relação entre o que se diz, como se realiza o dito, para quem e desde onde.

Roberto Carlos está falando de si em rede nacional, num espaço que se funda na liberdade de expressão, constitucionalmente instituída, por ser um direito fundamental em uma sociedade democrática. Ao final da reportagem, ao ser 
perguntado sobre "Quem escreveria a biografia do Roberto Carlos com as bênçãos do Rei?”, o cantor devolve: "Eu (...)", retomando o que já havia sido antecipado sobre estar escrevendo sua história com muito mais detalhes, porque saberia o que sentiu: "Porque ninguém poderá dizer o que eu senti e o que eu passei. Desculpa a rima, porque isso aí só eu sei"9. No espaço de uma emissora privada, um rei, cantor, em um país republicano, fala sobre a repercussão de uma polêmica, que envolve sua vida pessoal, e que chega a um público que abrange diferentes lugares do território nacional, sem aprofundar as repostas, corroborando os enunciados já constituídos anteriormente pelos dois jornalistas.

Nesses espaços de fala, inscrevem-se instâncias enunciativas que compõem a subjetividade do entrevistado: o nome próprio, o adjetivo que substitui o nome e refigura o indivíduo de que se fala, por meio de sua recepção social, e a primeira pessoa do singular, eu. Um eu escreveria a biografia de Roberto Carlos, interlocutor, com as bênçãos do rei, sujeito da alocução. Ao mesmo tempo, do ponto de vista enunciativo, "Roberto Carlos", "rei" e "eu" são e não são um mesmo sujeito. Renata fala com Roberto Carlos, referindo-se a ele-mesmo, em terceira pessoa, "rei", instaurando uma relação dêitica, com graus de intimidade e distanciamento simultaneamente. Ao dizer "eu", ele atualiza tais hipóteses, porque não responde nem Roberto Carlos, nem rei. O "eu" que escreveria a biografia é uma subjetividade que falaria sobre Roberto Carlos com as bênçãos de um rei, a figura pública a ser narrada por uma figura divina, monárquica, na concepção de pergunta da jornalista. O seu eu individual, pessoal, a pessoa dessa narrativa, no entanto, criaria um distanciamento linguístico das duas nominações da figura pública. Além disso,

9 Roberto Carlos. Entrevista realizada em 27 de outubro de 2013. Entrevistadora: Renata Vasconcelos. Transcrição: Site Fantástico, G1. Disponível em: http://g1.globo. $\mathrm{com} /$ fantastico/noticia/2013/10/roberto-carlos-preparaautobiografia-e-diz-que-vai-falar-de-acidente-na-infancia. html. Acesso em: 24 de maio 2018. o "eu" do final da entrevista também não é o "Roberto", sem o Carlos, nome próprio e parcial pelo qual foi chamado pela jornalista, ao longo da conversa, gestando o grau de intimidade que constituiu a encenação midiática. A intimidade esteve proposta pela enunciação do nome próprio como meio de tratamento entre os locutores, ou seja, ficou sugerida a imagem discursiva e semiótica de que o entrevistado não tem problemas em ser íntimo. Outro aspecto a ser pontuado nesse sentido é que o locutor explica que seu incômodo com a biografia publicada não se deveu ao acidente; fala do tema, que, segundo a Renata, é delicado para ele. Como não são feitas incursões profundas sobre a personalidade do sujeito privado para o público, o público, que aloca os dois, no caso, torna-se um lugar de latência e potência para a constituição de uma singularidade heterogênea. O locutor não se autodenominou pelo nome próprio, de nascimento, nem pelo de batismo social, dado pela carreira como músico. Tratou-se por um “eu”. Aparentemente, nos termos da discussão de Paul Ricoeur, em $O$ si-mesmo como um outro, ele se posicionou como um eu que falou de um si (Roberto Carlos)-mesmo(rei) que lhe constitui como outridade: cantor. O locutor se vê como esses outros? Quem é esse eu pelo outro da polêmica?

$\mathrm{Na}$ entrevista concedida ao programa Roda Vida, uma das perguntas feitas pelo jornalista Marvio dos Anjos, ao biógrafo e historiador Paulo Cesar de Araújo, a outra parte, retoma o assunto da intimidade:

Marvio dos Anjos: "Paulo, chegou a ficar claro pra você em qual parágrafo você cometeu o crime? Por que que o caso foi parar na justiça, no criminal? O que que houve ali, foi o relato da doença da Maria Rita, ontem na entrevista do Fantástico, Roberto Carlos falou que não tem problema em falar do acidente da perna, da perda da perna

Jerônimo Teixeira: me permite um aparte que ele não usou a palavra perna. É significativo, "Foi um acidente, o meu acidente, jamais falou em perna"]. 
Exatamente. Eu queria saber de você qual foi o teu crime, como você cometeu, qual foi a arma? ${ }^{10}$

Uma das dificuldades enfrentadas no tratamento dos dados da entrevista do Roda Viva foi justamente a polifonia da linguagem que estrutura o programa, bem como o debate entre os convidados. Como é possível ver, na fala de Marvio está incrustrada a de Jerônimo Teixeira. Na resposta de Paulo Cesar de Araújo, as inserções são ainda mais recorrentes e concorrentes. Tratase de uma metodologia de entrevista, em que o mediador, Augusto Nunes, organiza o debate, indicando as vozes que falarão a seu tempo, sucessivamente. À medida que o debate vai se desenvolvendo, entretanto, os locutores interpelam e atravessam a fala dos demais, muitas vezes agindo simultaneamente, e ainda em diálogo com a entrevista do Fantástico, que se deu no dia anterior. A alocução, portanto, se constitui por sua heterogeneidade, pelo dialogismo plurivocal, o que também fica claro nas personalidades convidadas, as quais, além de representarem a si mesmas, representam instituições de onde provêm. Há um aprofundamento do tema. Mesmo que a maioria das perguntas tenham sido pensadas anteriormente, a conversa se desenvolve, e muitas são produzidas pela própria conversa. Umas mais que outras, apresentam um tom didático, o que é perceptível no modo como são lidas, na sua inteireza, na entonação, indicando a escolha e o perfil do jornalista, muitas vezes assumindo um tom de interrogação judicial, ou ainda comparando pontos de vista como meio de levar o entrevistado a repensar seu dito e até mesmo mudar sua opinião. Importa salientar que a entrevista do Roda Viva, diferentemente da do Fantástico, é ao vivo, em que as vozes duelam.

10 Paulo Cesar de Araújo. Entrevista realizada em 28 de outubro de 2013. Entrevistadores: Augusto Nunes, Anna Virgínia Balloussier, Alberto Dinis, Jerônimo Teixeira, Júlio Maria, e Marvio dos Anjos. Transcrição minha.
Isso fica claro na abertura do primeiro bloco, em que Augusto Nunes informa que o programa é assim transmitido para todo o país, pela TV Cultura, pela TV Brasil, pelas emissoras afiliadas e pelo portal Uol. A bancada nesse dia esteve composta por cinco jornalistas; Anna Virgínia Balloussier, editora assistente da Revista São Paulo, do jornal Folha de São Paulo; Alberto Dinis, editor do Site Observatório da Imprensa e do Programa Observatório da Imprensa, transmitido pela TV Brasil; Jerônimo Teixeira, antes nominado, editor de cultura da Revista Veja; Júlio Maria, repórter de música do jornal o Estado de São Paulo; e Marvio dos Anjos, já mencionado, diretor de redação do jornal Destak. Na parte mais alta do cenário, os tuiteiros convidados e Paulo Caruso, o cartunista que costuma realizar cartoons e caricaturas dos fatos e dos entrevistados não pode estar presente. Nunes faz a ressalva de que dois dos advogados de Roberto Carlos foram convidados, assim como os representantes do grupo Procure Saber, "que é formado por músicos famosos", "dentre eles Chico Buarque, Gilberto Gil e Caetano Veloso”, “e que se opõem à publicação de biografias que não contam com a prévia autorização do biografado" "11, os quais também foram procurados pelo Fantástico, mas não retornaram ${ }^{12}$. Salientamos que, na entrevista do Fantástico, Paulo Cesar de Araújo é nominado jornalista e historiador, por outro lado, nessa, do Roda Vida, biógrafo e historiador, marcando assim como o autor é reconhecido por cada uma das emissoras.

O espaço que tem o sujeito no centro é atravessado por essas vozes que representam as principais empresas de jornalismo do Brasil. O 11 Paulo Cesar de Araújo. Entrevista realizada em 28 de outubro de 2013. Entrevistadores: Augusto Nunes, Anna Virgínia Balloussier, Alberto Dinis, Jerônimo Teixeira, Júlio Maria, e Marvio dos Anjos. Transcrição minha.

12 Roberto Carlos. Entrevista realizada em 27 de outubro de 2013. Entrevistadora: Renata Vasconcelos. Transcrição: Site Fantástico, G1. Disponível em: http://g1.globo. com/fantastico/noticia/2013/10/roberto-carlos-preparaautobiografia-e-diz-que-vai-falar-de-acidente-na-infancia. html. Acesso em: 24 de maio 2018. 
único que tem uma orientação diferenciada dos demais é Alberto Dines, do Observatório da imprensa. $\mathrm{Na}$ apresentação de um e-book sobre o site, Observatório da Imprensa: Uma antologia da crítica de mídia no Brasil de 1996 a 2018, organizado por Pedro Varoni e Lucy Oliveira, Dines aponta:

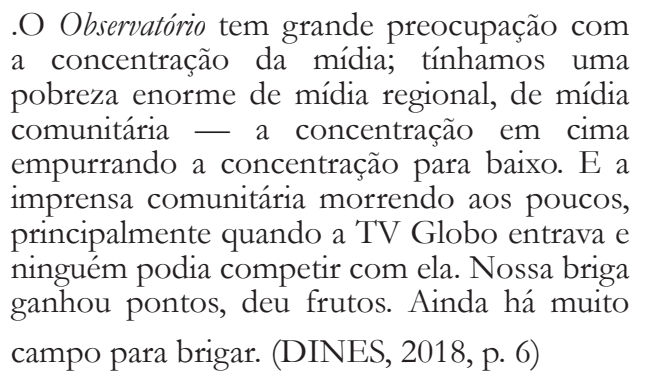

A política do Observatório é dialógica e crítica, uma vez que o site publica matérias de variados jornais, nacionais e internacionais, estes com versão traduzida. Na sua primeira fala, Dines não faz uma pergunta, mas pede licença para "um retrospecto de alguns séculos", indicando assim a terceira modalidade de entrevista que queremos propor: "expositiva auto-reflexiva". O jornalista situa o assunto criticamente e diz quê:

Alberto Dines: A gente está, todos aqui, brilhantes inteligências, é... é... discutindo Roberto Carlos, que aliás está na primeira página dos jornais de hoje como se fosse um guru cultural, não é, dando a sua opinião, "não, biografias tão autorizadas". Quem é Roberto Carlos no plano cultural? Você me desculpe, Paulo Cesar, eu sei que você é um admirador dele, mas ele é apenas um cantor, e compositor não é dos melhores que o Brasil já teve. Agora o que nós temos que ver é o seguinte: é uma sociedade inquisitorial. O Brasil durante trezentos anos teve três censuras simultâneas. Fomos um dos últimos países a ter permissão pra ter uma tipografia, no país, funcionando. É um dos últimos países a ter um jornal circulando. Nosso primeiro jornal foi impresso em Londres porque se não a inquisição ia lá, pegava. O que Roberto Carlos tá fazendo, ele é um herdeiro direto da inquisição. Não é à toa que ele é tão religioso assim, não é. Com essa... esse poder divino que ele tem de proibir. Ele não tem esse direito e eu acho que a imprensa tá incensando demais. Devia-se fazer é um... é um... é um protesto, sabe, boicotá-lo sim- plesmente. Porque um homem desses não tem o direito... não tem o direito de intervir na cultura de um país. Agora, infelizmente, infelizmente, ele tem o suporte de três figuras idolatradas, não é, Chico, Caetano [Augusto Nunes: Caetano] e Gilberto Gil [Augusto Nunes: Gil], e outros, o Mautner também, não é, e que dão um certo suporte que ele não tem pessoalmente [Jerônimo Teixeira: e não esqueça de Maluf, Bolsonaro e Feliciano] e também (risos). Então eu acho que nós temos que dar uma revertida nisso. O país não pode ter Roberto Carlos como um homem que diz o que é certo e errado em matéria de cultura. [Augusto Nunes: Perfeito] ${ }^{13}$.

\section{Com uma pergunta que intenciona} contrabalançar a primeira resposta de Araújo, e por outro lado, numa linha oposta à de Dines, o repórter do Estado de São Paulo, Júlio Maria, põe em dúvida a visão de Araújo sobre Roberto Carlos ter mudado ou não de opinião sobre a proibição das biografias, na entrevista ao Fantástico:

Júlio Maria: Paulo, é... mas você não vê na... na... atitude do Roberto, voltando pra entrevista de... do Fantástico uma sinalização ali pra, pra liberação, com ajustes? Quando ele fala em ajuste, a gente tem que lembrar que tem um Projeto de Lei na Câmara pra ser votado, prevendo agora um ajuste, ne? Quer dizer, libera-se a biografia, aé... mas ao mesmo te..., por outro lado, hã, hã, você tem o rito sumário que é a retirada dos livros, retirada não mais dos livros, mas o trecho da biografia, na próxima edição do livro, quer dizer, não tem mais censura prévia, mas cê pode retirar o trecho ofensivo na próxima edição, né?, e... a... a... a condenação de indenizações em tempo muito mais rápido do que é hoje. Seriam dois ajustes aí, a... a... já prontos pra que essa lei passasse no Congresso, isso vai ser votado até a semana que vem, segundo o autor do projeto, Nilton Lima, falou com a gente hoje. Você, a... a... não tá sendo um pouco, $a_{\ldots} \ldots a_{\ldots} a_{\ldots} \ldots h \tilde{a} \ldots$ pessimista demais a... a.. ao dizer que não tem papo com Roberto Carlos, ele quer que fique do jeito que está? O vacilo dele de domingo não sinaliza pra uma possível negociação? ${ }^{14}$

13 Paulo Cesar de Araújo. Entrevista realizada em 28 de outubro de 2013. Entrevistadores: Augusto Nunes, Anna Virgínia Balloussier, Alberto Dinis, Jerônimo Teixeira, Júlio Maria, e Marvio dos Anjos. Transcrição minha.

14 Paulo Cesar de Araújo. Entrevista realizada em 28 de 
Para Araújo, não. Maria pergunta se o biógrafo não estaria sendo pessimista, e se o biografado não poderia ter sinalizando para a concordância com a liberação. Entendemos tratar-se de um recurso de "contraposição", que pesa os dois lados, mas também põe em dúvida o entrevistado. Aqui o quarto exemplo da nossa tipologia. No entanto, pelo uso que faz das interjeições, o entrevistador hesita várias vezes a respeito de seus argumentos, o que poderia indicar incerteza ou insegurança no dito.

Augusto Nunes diz que a bancada quer dar a oportunidade de Araújo falar e assim expor seu lado da questão, explicitar o caso, bem como quer, ainda, expor os argumentos de quem não está presente, e nesse sentido as perguntas, que foram muitas, em virtude de um tempo de entrevista mais amplo, que precisou ser recortado em virtude do propósito desse artigo, versaram sobre saber o que incomodou o artista, quais os limites entre o que pode ou não pode ser dito sobre a vida de outra pessoa, o tema da censura, da invasão de privacidade, da defesa da liberdade de expressão, o assunto da autoria, do gênero biográfico, da luta do autor, Araújo, pelo resgate da biografia como tal, assim como a discussão do trabalho do jornalista biográfico, sua relação com a academia, e também as leis nacionais e internacionais sobre liberdades. Algumas vezes, as perguntas perfilam a cena de um "inquérito", quando se está em busca de uma suposta verdade, um quinto tipo metodológico a ser acrescentado. Araújo, em suas respostas, faz largo uso de "porquês". Seu tom é brando, e em nenhum momento se altera, mas é enfático em defender seu trabalho e seu personagem. Para tanto, o entrevistado, por meio do uso particular da sintaxe da língua, dá a sua locução um teor explicativo. Ele se explica, confessa-se, como se tivesse que dar conta de um crime, defender-se outubro de 2013. Entrevistadores: Augusto Nunes, Anna Virgínia Balloussier, Alberto Dinis, Jerônimo Teixeira, Júlio Maria, e Marvio dos Anjos. Transcrição minha. ou ainda redimir-se de uma culpa. Ocupa, por sua vez, a posição de réu em relação ao rei, o que está figurado no título de seu livro $O$ réu e o rei, minha história com Roberto Carlos.

Nesse grau de sua subjetividade é que expõe, a partir da pergunta de Marvio, acima transcrita, que seus crimes foram dois: $1^{\circ}$. ter dado existência à história de vida de uma personagem que tem Transtorno Obsessivo Compulsivo (TOC), que costuma controlar tudo e todos a sua volta, e $2^{\circ}$. ganhar dinheiro com a vida do cantor. Araújo diz que o cantor é um empresário, e que não admitiu que ele lucrasse com a sua história. Como Roberto Carlos disse ao Fantástico:

Roberto Carlos: O biógrafo também pesquisa uma história que está feita. Que está feita pelo biografado. Então ele na verdade ele não cria uma história. Ele faz um trabalho e narra aquela história que não é dele. Que é do biografado. E partir do que ele escreve, ele passa a ser dono da história. E isso não é certo.

Renata: Por uma questão também comercial?

Roberto Carlos: Por tudo.

Roberto Carlos: Pessoas têm dito que eu sou contra por causa do meu acidente, que foi contado, essas coisa toda. Não é isso, não. Eu quando escrever meu livro eu vou contar do meu acidente. Ninguém poderá contar do meu acidente melhor que eu. Ninguém poderá dizer aquilo que aconteceu com todos os detalhes que eu posso. Porque ninguém poderá dizer o que eu senti e o que eu passei. Desculpa a rima, porque isso aí só eu sei. ${ }^{15}$

Todos esses embates nos levam a alguns questionamentos: A quem pertence uma história de vida? Como se inscrever no discurso para falar do outro? Uma narrativa é a vida? É possível atribuir

15 Roberto Carlos. Entrevista realizada em 27 de outubro de 2013. Entrevistadora: Renata Vasconcelos. Transcrição: Site Fantástico, G1. Disponível em: http://g1.globo. $\mathrm{com} /$ fantastico/noticia/2013/10/roberto-carlos-preparaautobiografia-e-diz-que-vai-falar-de-acidente-na-infancia. html. Acesso em: 24 de maio 2018. 
valor, vender uma biografia? Quem escreve é dono da palavra? E quem a vive, da história? "Melhor" e "certo", como soam essas palavras no século XXI, depois dos estudos culturais, dos estudos da outridade, da compreensão de que a linguagem é polifônica, temperada com a multiplicidade das vozes que se enunciam numa alocução discursiva? Como negar o olhar do outro que marca a diferença e a diversidade, a pluralidade dos gestos? Ainda é possível falar da vida como propriedade que não pode ser comercializada a menos que o artista assim deseje? A vida é um patrimônio? Existe uma relação de posse para com a vida e a palavra? A enunciação, que é a colocação da língua em funcionamento, conforme Benveniste, não seria uma apropriação particular do privado e do público, para dar a conhecer ao outro, ao leitor? Não é um/a escritor/a um/a problematizador/a dos temas do seu tempo?

O léxico usado por Roberto Carlos é próprio do jargão do mercado e do comércio. Ao proibir a biografia, ao censurar a circulação de livros, como fala Dines, revela um lado político e cultural da nossa sociedade, daí a importância da problematização/recepção desse caso como um sintoma de um horizonte de expectativas de época: questionar a tendência brasileira para a inquisição, sem perder de vista (bio)políticas que excluem o desejo do outro, para manutenção de um direito individual, o da propriedade privada, para o silenciamento, para o silêncio, de que o entrevistado lançou mão quando perguntado se permitiria a biografia escrita sobre ele. Roberto Carlos, como disse Araújo, não foi valorizado pela elite nacional, o que é corroborado por Dinis. Araújo, por sua vez, explicou que a importância do que ele chama o "fenômeno Roberto Carlos", seu tema e personagem de pesquisa, além de ídolo de vida, merecia um lugar de destaque. Fato é que essa versão de si-mesmo o incomodou. Ao estudar um tema como esse, é importante considerar que, como diz Paul Ricoeur, as histórias de vida de uns estão emaranhadas nas de outros, sem subestimar, que, mesmo assim, até 2015, quando mudou a lei no Brasil para a publicação de biografias, que não precisam mais de autorização prévia, uma subjetividade tinha sua vida como um patrimônio não corporeificável na linguagem de outrem e na cultura.

\section{Subjetividade, Cultura, (Bio)Política}

Desde esses três eixos temáticos, podemos pensar a entrevista como um ato enunciativo de colocação da língua em funcionamento. As apropriações particulares demonstram nela, ou no discurso, sua capacidade de problematizar a cultura e também de se construir com ela. Por essa razão, a língua apropriada para formular uma entrevista, enquanto gênero, que se mostra tipologicamente variado, a partir da influência dos agentes e dos suportes que nele incidem, é uma língua social, como refere Bakhtin, ao tratar da heteroglossia do romance. Seja do ponto de vista da forma, seja a partir do conteúdo, mesmo quando a forma é proposta por meio de uma metodologia cara a cara, sem a diversidade de pessoas que falam, como é o caso da entrevista do Fantástico, o gênero entrevista midiática é polifônico. E é justamente sua classificação como um gênero do discurso que faz com que se apresente de forma variada, uma vez que duas das características do discurso são o dialogismo e a plurivocalidade, dada a multiplicidade de maneiras pelas quais sujeitos se inscrevem e produzem atos de fala. Sendo assim, a sociedade, ao atuar na língua colocada em funcionamento, temporalmente, sucessiva ou simultaneamente, constrói um espaço biográfico, que nos permite entender a hibridez dos ditos, as políticas, os suportes, assim como mídias, meios e mediações. 
Interessa acrescentar aqui ainda a autoficcionalidade como um atributo do caráter do gênero. Não só as pessoas que enunciam, mas o jogo gestual e semiótico que precede a encenação da relação pergunta-resposta, permite que os personagens e os espaços construam uma autoimagem, desde o sair de si até o outro, num processo de enunciação hermenêutica, pelo ato de confissão, que, como discute Foucault, por assim dizer, não é um ato espontâneo uma vez que se estrutura pela figuração de um poder (bio)político; uma técnica de si.

Nesta investigação, portanto, buscamos entender os processos culturais e sociais de subjetivação que emanam das vozes e falas, na relação entrevistador-entrevistado, da mesma forma, por meio da prática escrita, o ato da observação concretizado, pela seleção do que foi dito, sempre no dilema entre o plausível e o possível, ou o verossímil. Na escuta dos sujeitos, com seus pressupostos e subentendidos, perceber as fontes e assim armar a trama dos argumentos, no sentido de dar a conhecer o que se estuda e assim encontrar o diálogo. Nesse caso, para pensar o absurdo, como falou Araújo, de, no século XXI, um livro ser proibido de circular em uma sociedade democrática de direito, pondo em xeque a liberdade de expressão, tema esse que perpassou as duas entrevistas.

Os onze mil exemplares de Roberto Carlos em detalhes, segundo o biógrafo, foram recolhidos para um galpão, por um caminhão do biografado. Os absurdos, no entanto, devem ser investigados sob pena de serem naturalizados como verdade, passando a serem alegóricos, ou seja, tornandose verdade aceitável. O caso das biografias foi contundente por que politicamente o que esteve ameaçado foi a democracia nacional: a Constituição e o direito dos cidadãos. A lei que vigora desde 2015 e que pôs fim à necessidade de autorização prévia para a escrita de biografias no país impediu que a democracia e o estado perdessem com isso. No entanto, o episódio focalizou um traço particular da personalidade social brasileira, identificado pelo jornalista Dines, de ser inquisitiva, ao que seria possível associar a aptidão para a confissão e a explicação, e que justificaria os tronos e o sucesso dos reis e rainhas que ainda são nomeados no Brasil, em diferentes contextos. Temos uma vocação para a vassalagem, para a inquisição, para a censura, para o anti-intelectualismo, o que se explica pelo baixo número de leitores, a ponto de termos de discutir a gravidade que é um livro ser impedido de circular.

Roland Barthes em O rumor da lingua diz em "O processo que se move periodicamente", que "o anti-intelectualismo é um mito histórico, ligado sem dúvida à ascensão da pequena burguesia” (BARTHES, 2004, p. 425). Para o escritor, "as tarefas do intelectual são definidas por essas resistências mesmas, lugar de onde elas partem; Brecht formulou-as diversas vezes: trata-se de decompor a ideologia burguesa (e pequenoburguesa)" (BARTHES, 2004, p. 425-426). Além disso, "de estudar as forças que fazem mover-se o mundo e de fazer progredir a teoria". (BARTHES, 2004, p. 426) A língua, a linguagem e o discurso são maneiras de problematizar práticas sociais cristalizadas, de pensar sobre os valores que as empoderam, que sugerem tornar a leitura um patrimônio. $\mathrm{O}$ material de trabalho de um escritor e de uma escritora é a palavra. Segundo também disse Barthes, "o intelectual se assume como um ser de linguagem" e portanto um ser que "perturba a segurança de um mundo que opõe soberbamente as 'realidades' às 'palavras', como se a linguagem fosse para o homem somente o cenário vão de interesses mais substanciais" (BARTHES, 2004, p. 426). Como diz o título do livro de Leonor Arfuch (2008), a crítica cultural está entre a política e a poética. Para além de somente análise de conteúdo, é necessário pensar as formas dos conteúdos, os gêneros, assim como os meios, os 
suportes e os métodos que os estabilizam num determinado formato. Refletir sobre as formas em uma sociedade, especialmente quando signos como público e privado fazem surgir binômios como íntimo/externo, dentro/fora, implica pensar as subjetividade das formas e as paixões dos sujeitos e seus enunciados. Além disso, a performance das práticas, por sua vez, políticas.

O perfil do programa e da empresa que veicula as entrevistas quando o faz constrói pela linguagem imagens de outredade. Por essa razão, o aparelho de funções de Benveniste não nos permite apenas estudar como se comporta o discurso, mas como esse discurso em funcionamento faz funcionar as trocas político-culturais de uma sociedade, pondo-a em agenciamento. As estruturas de poder regulam as mídias, não somente as estatais. No caso das entrevistas investigadas, há a presença da interrogação e da asserção, uma vez que nenhum dos dois entrevistados foi intimado a falar, a não ser pela contingência do tema. Com relação ao modo sucessivo ou simultâneo como ocorrem os atos de fala, a entrevista do programa Roda Viva demonstra a presença das duas situações, com predominância da simultaneidade de atos de fala. A do Fantástico apresenta a sucessividade temporal. Um locutor enuncia a seguir ao outro, sucessivamente. Cada uma delas, por isso, ficcionaliza, na performance do discurso, o que entende por sociedade, situação de comunicação, atos políticos, sociabilidade e entrevista. Também apresentam tipologias que resultam da metodologia empreendida pelo entrevistado, conforme a orientação ideológica de cada emissora e particular de cada jornalista.

O episódio da proibição dessa biografia publicada em 2006 nos ajuda a pensar o país na atualidade. Desde então, a democracia vem sofrendo constantes ataques em sua constituição, assim como a presença do judiciário nas causas públicas tem se tornado cada fez mais reiterada, assumindo protagonismos midiáticos em muitas decisões. Seria possível arriscar uma hipótese de que esse caso é um marco histórico, cujas decisões puseram o país em alerta para os ataques que vieram a seguir. A liberdade de expressão talvez tenha sido o que motivou o incensamento que descontentou Dines. Cada um viu nesse episódio uma forma de projetar a defesa de suas particularidades e ganhar e/ou dar visibilidade com/para a discussão. A mídia, o judiciário, os artistas, todos estiveram envolvidos nessa ordem perigosa do discurso.

Muitas vezes nessa caminhada de investigação que iniciamos em 2015, quando começamos a investigar o gênero biográfico e o processo que se move contra escritores, surgiunos a questão de como tratar o assunto, como abordar as fontes. Dessa vez não foi diferente, pois o trabalho sustenta-se a partir de entrevistas feitas por outrem e não em primeira pessoa, como é comum ao campo da história oral. Leonor Arfuch em seu El espacio biográfico, Dilemas de la subjetividade contemporânea (2010), quando trata do espaço biográfico nas Ciências Sociais, diz que: "el historiador Michelet recogía em Le peuple (1846) los relatos de gentes del Pueblo de toda Francia, inaugurando así la práctica que más tarde se definiria como história oral (ARFUCH, 2010, p. 180).

A história oral é também uma história do discurso. O que podemos dizer da entrevista. Pode estar no jornal e na fala recolhida por outrem. A entrevista midiática, nesse sentido, tem sua contribuição, como fonte para pensar os silêncios, os gestos, as elipses, as argumentações, as presenças, as ausências, os pressupostos, os subentendidos, a gramática, os verbos, o si e os outros, as performances, os meios e os suportes. O espaço biográfico, e autoficcional, do gênero entrevista midiática nos permite entender as subjetividades, a política e a cultura, pensar o sujeito no centro de uma arena ou o sujeito em um estúdio de gravação. São metáforas que nos levam a propor uma tipologia - dado o caráter do 
gênero -, aberta, que visibilizam espacialmente os modos de sociabilidade produzidos pela mídia: 1 . onisciente ou didático-demiúrgica, 2. atestação da verdade enunciada, 3. expositiva auto-reflexiva, 4. contraposição, 5. inquérito.

Enquanto gênero, a entrevista contribui para discutirmos como se produz conhecimento, como se constrói sentido, se é possível ou não se acercar da verdade, especialmente, do sujeito, muitas vezes visto como repositório do saber, outras como referência para um discurso previamente formulado, indagados por personalidades, para resolver suas dúvidas sobre um determinado fenômeno social, ratificando muito mais o sentido comercial do veículo do que os fenômenos políticosociais e suas problematizações. Dar a conhecer no caso da transcrição também é uma versão do outro por meio da palavra escrita. A história escrita da oralidade está atravessada por ficções ou produções de verdades, com intenções dialógicas e tem sido assim desde Homero. A entrevista corporifica o social como forma e conteúdo. Os poetas foram os primeiros locutores a dar voz à oralidade. E hoje continuamos a buscar poéticas da mesma forma, como a que estamos propondo. A entrevista é uma fonte, pois, para saberes heterogêneos de como as falas configuram e reconfiguram alocuções, sujeitos e culturas.

\section{REFERÊNCIAS}

ARFUCH, Leonor. El espacio biográfico. Dilemas de la subjetividad contemporánea. Buenos Aires: Fondo de Cultura, 2010.

ARFUCH, Leonor. La interioridad pública. La entrevista como género. Buenos Aires: Cuaderno, Instituto de Investigaciones Facultad de Ciencias Sociales (UBA), 1992.

BAJTIN, Mijail. Estética de la creacion verbal. Buenos Aires: Siglo XXI, 2018.
BARTHES, Roland. O processo que se move periodicamente. In: O rumor da língua. São Paulo: Martins Fontes, 2004. p. 425-426.

BENVENISTE, Émile. O aparelho formal da enunciação. In. Problemas de lingüística geral II. São Paulo: Pontes, 1989. p. 81-90.

FOUCAULT, Michel. El origen de la herméutica de sí. Conferencias de Dartmouth, 1980. Buenos Aires: Siglo Veintiuno, 2016.

MUNHOZ, Eliana Regina. A Rede Globo de Televisão no território brasileiro através do sistema de emissoras afiliadas. São Paulo: 2008. Disponível em: $\quad$ file:///C:/Users/User/Downloads/ ELIANE_REGINA_MUNHOZ.pdf. Acesso em: 24 de maio 2018.

RICOEUR, Paul. O si-mesmo como um outro. Trad. Luci Moreira Cesar. Campinas: Papirus, 1991.

VARONI, Pedro, OLIVEIRA, Lucy Oliveira (Orgs.). Observatório da Imprensa: Uma antologia da crítica de mídia no Brasil de 1996 a 2018. São Paulo: Casa da Árvore, 2018.

\section{ENTREVISTAS}

GLOBO PLAY. Fantástico. Roberto Carlos fala sobre polêmica das biografias. Disponível em: https://globoplay.globo.com/v/2916608/. Acesso em: 24 de maio 2018.

RODA VIVA. Disponível em: https://www. youtube.com $/$ watch?v $=$ MbbljTpgcdo. Acesso em: 24 de maio 2018. 